\title{
2
}

\section{Is Aesthetic Experience Possible?}

\author{
Sherri Irvin
}

On several current views, aesthetic appreciation or experience involves second-order awareness of one's own mental processes. Matthew Kieran says, 'When we truly appreciate a work, we appreciate its pictorial composition, the arc of the lines, the shading, the foreshadowing, the ways in which the artistry shapes and guides our responses' (Kieran 2005: 213; emphasis added). Gary Iseminger suggests that ' $[\mathrm{s}$ ] omeone is appreciating a state of affairs just in case she or he is valuing for its own sake the experiencing of that state of affairs', and is thus in 'the aesthetic state of mind' (Iseminger 2005: 99; emphasis in original). Jerrold Levinson suggests that valuing an experience in itself, in Iseminger's sense, might be cashed out as 'tak [ing] satisfaction in such an activity for its own sake while, at some level, endorsing or approving doing so' (Levinson forthcoming; emphasis in original). Thus, in Levinson's version, we have the experiencing of a state of affairs, the taking of satisfaction in this experiencing, and the endorsing of one's satisfaction.

Levinson ultimately holds that higher-order valuing of one's own experience is only one variety of aesthetic experience, though. He says, 'Aesthetic experience is experience involving aesthetic perception of some object, grounded in aesthetic attention to the object, and in which there is a positive hedonic, affective or evaluative response to the perception itself or the content of that perception' (Levinson forthcoming; emphasis in original). Since a positive response to the content of the perception is sufficient, second-order awareness is not required for all forms of aesthetic experience. Noël Carroll, like Levinson, incorporates second-order awareness into his account of aesthetic experience, but without making it a requirement: 'attention with understanding...to the ways in which [the work's formal and aesthetic properties] engage our sensibilities and imagination' is one variety of aesthetic experience, but simply attending to those formal and aesthetic properties themselves, without any second-order awareness, is another (Carroll 2002: 167).

But what if it turns out that we don't have introspective access to the processes by which our aesthetic responses are produced? What if we are, in fact, very poor judges 
of how the artistry of a work 'shapes and guides our responses', as Kieran puts it? ${ }^{\text {? }}$ There is good reason to think that we are, in fact, poor judges of such things. In a famous paper, Nisbett and Wilson (1977) surveyed results suggesting that we are ignorant of major swathes of what happens in our minds and why, though we nonetheless make confident claims about these matters. We are unaware of crucial factors that enable us to solve problems, that cause us to prefer one item to another, and that significantly influence our major life decisions. As Nisbett and Wilson sum things up, 'Subjective reports about higher mental processes are sometimes correct, but even the instances of correct report are not due to direct introspective awareness. Instead, they are due to the incidentally correct employment of a priori causal theories' (233). Though we believe that we are consulting our introspective memories when we explain our judgements, decisions, or actions, we are in fact constructing post hoc rationalizations.

Nisbett and Wilson's paper triggered many subsequent studies with troubling implications for the domains of aesthetic experience and judgement. ${ }^{2}$ I will describe what I take to be the problems revealed by these studies and consider the implications of these problems for our understanding of aesthetic experience and appreciation.

\subsection{The Bad News, and a Little Good News}

Here are the problems, as I see them. First, irrelevance: subjects' aesthetic or proto-aesthetic preferences are strongly affected by conditions that are aesthetically irrelevant. So, for instance, Cutting (2003) was able to alter his subjects' preferences among Impressionist paintings simply by manipulating how frequently various paintings appeared in their environments. ${ }^{3}$ Even more strikingly, when Nisbett and Wilson (1977) asked subjects in a discount store to rate the quality of four pairs of stockings that were in fact identical, spatial position had a large effect on rankings: 12 per cent of subjects preferred the stockings on the left, 17 per cent those second from the left, 31 per cent those second from the right, and 40 per cent those on the right. Similar effects were seen for nightgowns. ${ }^{4}$ Position, obviously, is irrelevant as a reason to prefer one pair of stockings or one nightgown to another. Finally, Yamada (2009) suggests that a reversal of preference can be achieved by asking subjects different questions about the stimuli. Subjects were asked to compare an abstract and a representational painting. When asked to verbalize their reasons for liking the paintings, they preferred

\footnotetext{
In section 2.2, I discuss a weaker interpretation of Kieran's requirement.

${ }^{2}$ See also related discussion in Lopes (this volume). In section 2.2 I discuss the relevance of these studies specifically to the aesthetic domain.

${ }^{3}$ Subjects tended to prefer paintings to which they were exposed more frequently. We must use caution in seeing Cutting's study as providing evidence of an irrelevance problem: the results may have been due not to a mere exposure effect, but to subjects' having more opportunity to grasp the genuinely valuable features of the paintings. Kieran, Meskin, and Moore (unpublished) found that exposure decreased subjects' liking for bad paintings (by Thomas Kinkade).

${ }^{4} \mathrm{Li}$ and Epley (2009) discuss the relevance of memory to position effects and show that serial position has a different effect on choices among desirable options than on choices among undesirable options.
} 
the representational painting. When asked to verbalize their reasons for disliking the paintings, they preferred the abstract painting. Which question one is asked, however, is irrelevant as a reason for preferring one to the other.

The subject's own characteristics, too, can be a source of irrelevance effects. Right-handed subjects judge that paintings with visual interest on the right are 'more aesthetically pleasing', while left-handed subjects prefer visual interest to the left (McLaughlin et al. 1983: 149). One's handedness is clearly irrelevant to the value of artworks one may be judging.

The second problem is coarse-grainedness. Aesthetically relevant aspects of a work fail to have the expected effects on people's judgements. Nisbett and Wilson (1977) gave subjects a selection from John Updike's novel Rabbit, Run. Some subjects read the entire selection, while others read versions that had various significant passages deleted. However, subjects in all conditions rated the selection as having the same degree of emotional impact. This suggests that the subjects' response to the work was not responsive to specific details in the way that artists presumably hope when they carefully refine their works. ${ }^{5}$

Studies of the visual perception of paintings, too, support the idea that much aesthetic judgement is coarse-grained. Locher et al. (2007) found that ratings made after 100 millisecond exposures to paintings are highly correlated with ratings made after unlimited exposure. Eye movement analysis showed that initial reactions during unlimited exposure were based on exploration of only 27 per cent of the work. Moreover, in the entirety of the unlimited exposure phase 'approximately $54 \%$ of the pictorial fields were not directly fixated or did not receive sustained fixation' (p. 75). Subjects neglected large portions of the artwork, and their ratings were based primarily on details cursorily taken in during very early phases of exposure, and not substantially updated after fuller study.

The third problem is ignorance. Subjects tend not to know whether a particular condition has affected their judgement. Subjects in the Rabbit, Run study believed, incorrectly, that the passages that were deleted in some conditions influenced, or would have influenced, their judgements of emotional impact. Subjects in another study by Nisbett and Wilson mistakenly believed that their judgements of a documentary had been altered by a distracting noise outside the theatre, but in fact, their ratings were the same as those of subjects who saw the documentary without the noise. Subjects in the stocking study were unaware that the position of the stockings had affected their judgements; indeed, they were incredulous at the suggestion. ${ }^{6}$ In some studies, the ignorance extends even more deeply: subjects who are induced to change their

\footnotetext{
${ }^{5}$ Nisbett and Wilson's interest was in people's poor understanding of which aspects of the work contribute to their responses; they were not aiming to demonstrate coarse-grainedness. It is possible that their measure was itself too coarse-grained to capture the nuances of subjects' responses.

${ }_{6}$ ' $[\mathrm{W}]$ hen asked directly about a possible effect of the position of the article, virtually all subjects denied it, usually with a worried glance at the interviewer suggesting that they felt either that they had misunderstood the question or were dealing with a madman' (Nisbett and Wilson 1977: 244).
} 
evaluation of something often fail to recognize not only what has been responsible for the change, but even that the change has happened at all: they incorrectly recall having held their current evaluation all along.7 Subjects are also ignorant of the factors that influence problem solving: in a classic experiment (Maier 1931), subjects had to find multiple solutions to a problem, and one of the more difficult solutions involved swinging a cord. Very few subjects found this solution before an experimenter 'casually put one of the cords in motion' (Nisbett and Wilson 1977: 241), but nearly everyone found it within 45 seconds thereafter. Two-thirds of subjects were completely unaware that the cue had helped them solve the problem. Even on direct questioning subjects are sometimes adamant that they were not influenced by a factor that, statistically, clearly had a strong effect on most. ${ }^{8}$

The fourth problem is confabulation. People are unaware that they lack good introspective access to the factors that influence their judgements, and they provide confabulated 'explanations' of their choices. In the stocking study, subjects attributed their ratings to differences in the 'knit, weave, sheerness, elasticity, or workmanship of the stockings', though the stockings were in fact identical in these respects. Nisbett and Wilson (1977, esp. p. 241) report that such spurious explanations are common. Subjects apparently rely on theories about which factors are relevant to judgement in fabricating such explanations.

The fifth problem is explanation-induced instability. When subjects try to report on the mental processes that have influenced their judgements, this changes what they report preferring: a subject asked to explain her preference is likely to say that she likes a comical poster better than a poster of an Impressionist painting, but subjects not asked to explain tend to hold the opposite preference (Wilson et al. 1993). Johansson et al. (2005) asked subjects to report their preference between two faces, X and Y. Some subjects who reported preferring $\mathrm{X}$ would later be asked to explain why they (allegedly) preferred Y. For the subject even to notice that she was being asked to explain a preference that she did not hold was rare; and her explanation would often invoke features of $\mathrm{Y}$ that were not also possessed by $\mathrm{X}$, showing that she was not reporting on an introspective process that generated the initial preference. Moreover, after being asked to 'explain' her 'preference' for $Y$, the subject typically would express a preference for $\mathrm{Y}$ if subsequently asked to compare $\mathrm{X}$ and $\mathrm{Y}$ again (Hall and Johansson 2008). The study described above, in which preferences shifted depending on whether subjects were asked to describe what they liked or disliked about paintings, suggests that subjects rely on the easiest factors to verbalize: positive and negative reasons are easier

\footnotetext{
7 Nisbett and Wilson (1977: 235-7), discussing Bem and McConnell (1970) and Goethals and Reckman (1973).

${ }^{8}$ This is particularly true of the well-known bystander research by Latané and Darley (1970), who demonstrated that people are much less likely to offer help when they believe that many others are also in a position to do so. See Nisbett and Wilson (1977: 241) for discussion.
} 
to articulate in relation to figurative paintings than in relation to abstract paintings (Yamada 2009).

The sixth problem is explanation-induced deterioration. When preferences change as a result of explanation, they are lower in quality from two perspectives. First, the preferences are less likely to match those of experts. ${ }^{9}$ Second, subjects are less likely to be satisfied by their choices. Subjects who chose the comical poster were less likely to have hung it, reported liking it less, and were willing to sell it for a lower price (Wilson et al. 1993).

There are two shreds of slightly better news. The first is correct explanation. People frequently offer correct explanations of their choices. The experiments in which people offered false 'explanations' were designed to exploit discrepancies between subjects' choice processes and the explanations they were likely to offer. People aren't usually asked to perform absurd tasks like ranking the quality of identical stockings. In a real-world choice situation, actual differences in knit, weave, sheerness, and elasticity presumably would affect subjects' rankings, and they would not be forced to invent a story about these features.

However, the comfort we should take from this is limited. First, many correct explanations seem to be produced through theorizing rather than introspection, but subjects nonetheless believe they are offering introspective reports. Confabulation remains an issue. Second, if position effects are so strong in the absurd choice situation, they are presumably also present, though perhaps less pronounced, in ordinary situations. Irrelevance and ignorance thus remain in play: subjects' responses are driven in part by irrelevant factors of which they are unaware.

The second shred of slightly better news, call it differential susceptibility, is that some people, particularly experts in a domain, are less susceptible to some of these effects. ${ }^{10}$ The results of the studies are consistent with the existence of a subgroup of people who are better at filtering out aesthetically irrelevant information and/or recognizing what has truly affected their choices. ${ }^{11}$ The studies leave open the possibility of a minority with significant introspective access to their choices. A third of the subjects in Maier's (1931) problem-solving study involving the swinging cord reported, correctly, that the experimenter's bumping the rope had helped them solve the problem. ${ }^{12}$ Fleming et al.

\footnotetext{
9 Wilson and Schooler (1991) made this finding in studies about preferences for strawberry jam and for college courses.

${ }^{10}$ E.g., Carlson and Bond (2006) and Coupey et al. (1998) note that experts are less susceptible to preference instability due to irrelevant shifts in context.

${ }^{11}$ However, Mantonakis et al. (2009) found that while both high- and low-knowledge subjects were susceptible to a rather steep primacy effect in wine preferences (that is, a tendency to prefer the wine presented first in a series), high-knowledge subjects were also subject to a recency effect (tendency to prefer the wine presented last).

${ }_{12}$ As Nisbett and Wilson (1977: 241) note, however, these correct reports may have been guesses based on external theories of problem solving rather than introspection.
} 
(2010) suggest that there are individual differences in introspective awareness of mental processes, and that these correspond to differences in brain structure. ${ }^{13}$

To sum up, here are the problems and bits of slightly better news.

The bad news:

1. Irrelevance: aesthetic responses are determined in part by aesthetically irrelevant conditions.

2. Coarse-grainedness: aesthetic responses are excessively coarse-grained, failing to take into account aesthetically relevant aspects of the work.

3. Ignorance: we don't know what causes our aesthetic responses.

4. Confabulation: we don't know that we don't know what causes our aesthetic responses, and we offer confabulated 'explanations'.

5. Explanation-induced instability: when we try to offer explanations, this changes our preferences.

6. Explanation-induced deterioration: preferences formed after explanation are lower in quality.

The slightly better news:

1. Correct explanation: people often explain their choices correctly, though mostly through theorizing rather than introspection. This good news has limited ability to mitigate the bad news, since subjects still believe they are introspecting.

2. Differential susceptibility: there seem to be subgroups of people who are less susceptible to some of the problems, and who have greater introspective access to their mental processes.

\subsection{Why These Are Problems for Aesthetics}

In the studies discussed above, subjects were asked to report on liking or disliking of an artwork or other object, to express a preference between objects, to make choices about whether to acquire or keep an object, or to make judgements of quality regarding non-art objects. How are such measures related to aesthetic experience and appreciation?

Liking, preference, and choice might come apart from aesthetic judgement in particular cases. I nonetheless regard these measures as at least proto-aesthetic, in the absence of evidence to the contrary. First, there is surely an intimate relationship between an experience of aesthetic value and an experience of liking, pleasure, or preference, even if the correlation is not perfect. Traditional accounts of aesthetic value

\footnotetext{
${ }^{13}$ Specifically, introspective awareness is correlated with gray-matter volume and white-matter microstructure in the anterior prefrontal cortex (Fleming et al. 2010). Subjects were asked to perform a difficult task, and then to rate their confidence in their answers. Subjects were rated as high in introspection if they were significantly more confident about their correct answers than their incorrect answers.
} 
have often defined it in terms of the production of pleasurable states (e.g., Bell 1914; Hume 1757/1985).

Second, consider the specific tasks the subjects performed. They were asked to 'look at each pair and judge which image they liked best' (Cutting 2003: 328); 'choose the piece they liked [or disliked] the most' (Yamada 2009: 1141); 'choose the member of each pair they found more aesthetically pleasing' (McLaughlin et al. 1983: 149); rate 'the pleasingness of' each image (Locher et al. 2007: 63); rate 'how much they liked each poster' and 'choose whichever one [they liked] the best' (Wilson et al. 1993: 333 and 334); 'choos[e] which face in each pair they found most attractive' (Hall and Johansson 2008: 269); say 'what emotional impact [a literary passage] had had' (Nisbett and Wilson 1977: 245); and judge a documentary with regard to 'how interesting they thought it was, how much they thought other people would be affected by it, and how sympathetic they found the main character to be' (Nisbett and Wilson 1977: 245). Most of these tasks invite subjects to focus directly on their experiential encounter with the object, which is of interest in relation to theories of aesthetic experience and appreciation. How 'aesthetically pleasing' an image is, how 'attractive' a face is, the 'emotional impact' of a literary passage, and 'how interesting' a documentary is all seem directly relevant to aesthetic assessment. It is true that judgements of how much an image is liked, or how pleasing it is, could come apart from aesthetic assessment: a subject might prefer, or find more pleasing, a landscape she regards as aesthetically mediocre in comparison to an aesthetically superior painting of a rotting carcass. But Cutting's (2003) subjects, for instance, were comparing pairs of Impressionist paintings with similar techniques and subject matters, so there is no reason to think that the factors that would separate liking from aesthetic assessment were in play.

Some of Nisbett and Wilson's (1977) subjects were asked to 'say which article of clothing was the best quality' (p. 243). Intuitively, judgements of quality in garments like stockings and nightgowns are not aesthetic judgements: they involve criteria related to both appearance and durability. But there is no obvious reason aesthetic judgements would be immune to position effects to which judgements of quality succumb.

In sum, preference and liking are surely correlated with, even if not identical to, aesthetic assessment. In the absence of reasons to expect systematic reversals of this relationship, it is reasonable to expect that factors influencing preference and liking will influence related aesthetic phenomena.

How do the problems outlined above cause trouble for accounts of aesthetic appreciation and experience? On views requiring that artworks be correctly apprehended, it seems that anyone afflicted by irrelevance, and possibly also coarse-grainedness, could not be appreciating a work aesthetically. In cases of irrelevance, it seems the object is perceived through a fog of irrelevant conditions that cause viewers to misapprehend it. Identical stockings, seen through the haze of the position effect, seem to differ in weave, elasticity, and sheerness. Coarse-grainedness, on the other hand, need not involve false beliefs about the object: it is not false to describe several different shades 
as 'red', or several different emotional timbres as 'sad'. But it does manifest a failure to apprehend the object fully enough for aesthetic purposes.

Carroll's account may imply that subjects susceptible to irrelevance are not having aesthetic experiences at all, even where second-order awareness is not in play. Carroll's account requires 'attention with understanding to the work's formal and aesthetic properties and[/or] their interaction with each other and[/or] to the ways in which they engage our sensibilities and imagination'. Subjects in the grip of irrelevance are attending without (much) understanding. Coarse-grainedness, too, involves a troublingly limited degree of understanding, though perhaps not enough to disqualify subjects completely. Appreciation, or the aesthetic state of mind, seems to be compromised by these problems on Iseminger's account as well. He says that 'the aesthetic state of mind... is the state of mind in which, while tracking [formal and expressive] features (among others...), one finds this tracking valuable for its own sake.14 But subjects in the grip of coarse-grainedness and, especially, irrelevance are not in fact tracking these features, though they may falsely believe that they are. Similarly, on Levinson's view that ' $[a]$ esthetic experience is experience involving aesthetic perception of some object, grounded in aesthetic attention to the object', it is unclear whether irrelevance and coarse-grainedness are consistent with aesthetic experience at all, since they seem to indicate that aesthetic attention to the object is seriously compromised or absent.

Kieran's account does not appear to treat coarse-grainedness as disqualifying subjects from aesthetic appreciation. However, the fact that we are ignorant of the processes that cause our aesthetic responses seems to be disqualifying on this account. Ignorance seems to rule out the possibility that we could appreciate 'the ways in which the artistry shapes and guides our responses', as Kieran requires. In correspondence, Kieran has suggested a weaker reading of his requirement, on which being aware that one's responses are being shaped by the work, even if one does not know how, might be enough. On this reading, ignorance alone would not threaten aesthetic experience, but the combination of ignorance and irrelevance would. For irrelevance raises the prospect that some (aspects) of our responses may not be caused by the work at all, but rather by conditions such as the way it is positioned in the museum. In combination with ignorance, irrelevance may prevent us from distinguishing the artistry's contribution to our responses from the contribution of other factors, as even Kieran's weaker condition seems to require.

Ignorance also calls into question the extent to which we could be valuing our experiencing of a state of affairs, as Iseminger requires: for the connection between the state of affairs and our experiencing is unclear.

The tendency to confabulate when we attempt to explain our responses may not add much, other than embarrassment, to the difficulties described above. Explanation-induced instability and deterioration do add something, though: they

\footnotetext{
${ }^{14}$ Iseminger (2005: 103).
} 
suggest that the problems will not be easy to solve, and attempts to solve them may be harmful. An obvious way to address irrelevance, coarse-grainedness, and ignorance is to try to pay closer attention to what is, in fact, going on in our minds. But explanation-induced instability and deterioration suggest that when we try to report on our mental processes, this alters their course and causes deterioration in the outcomes, undermining satisfaction.

\subsection{Aesthetic Experience, Aesthetic Appreciation, and Deep Aesthetic Appreciation}

Before considering further implications of problems with second-order awareness, I'd like to introduce some methodological constraints. The first is that on any acceptable account, it must turn out that aesthetic experience and appreciation are possible. The answer to the question posed in my title, then, is yes. Aesthetic experience and appreciation are important dimensions of human life. If an account of aesthetic experience or appreciation picks out phenomena that turn out not to be empirically viable, we should conclude that it has picked out the wrong things. We should be wary of accounts of aesthetic experience and appreciation developed without consulting relevant empirical evidence. ${ }^{15}$

Further, aesthetic experience and appreciation should not turn out to be rare, exalted states accessible only to art experts or the preternaturally gifted. Ordinary people have aesthetic experiences on a fairly regular basis. These include admiring a garden in full bloom, having one's breath taken away by the beauty of one's sleeping child, and listening with enjoyment to music on the radio. When people attend to, respond to, and take pleasure in the form and content of music as they listen, sing along, and dance, they are responding aesthetically, even if they lack a sophisticated capacity to describe the elements of the music, or to explain or justify the components of their responses. ${ }^{16}$ Similarly, ordinary people can appreciate many kinds of artworks, ranging from popular music to paintings in museums. Some works may be so complex or difficult that only a few people can appreciate them, but such works are the exception.

We can still distinguish everyday responses from more sophisticated aesthetic engagement with artworks. Indeed, there are two distinctions it will be helpful to make. The first is between aesthetic experience and aesthetic appreciation. In my view, aesthetic appreciation is focused on its object: it is appreciation of that object, and as such the object must be largely correctly apprehended. It is desirable, however, to have a more permissive account of aesthetic experience, such that one can have an aesthetic experience caused by an object that is seriously misunderstood, or even imagined (as

${ }^{15}$ Cf. Bergeron and Lopes (2012).

${ }^{16}$ For an excellent discussion of dancing as an aesthetic response to music, see Shusterman (1991). 
in the case of hallucinations). ${ }^{17}$ An aesthetic experience of an artwork may turn out to be sufficient for aesthetic appreciation of that artwork, as long as the experience has involved a sufficiently accurate grasp of the artwork..$^{18}$ An aesthetic experience that is triggered by an artwork, but in which the artwork has been seriously misunderstood, will not count as aesthetic appreciation of the work. The relation of aesthetic experience to aesthetic appreciation can be construed in a similar way for non-artworks.

A second distinction is between mere appreciation of an artwork and deep appreciation. Deep appreciation, which comes in degrees, is appreciation that demonstrates a grasp of such things as artistic technique, art-historical relations, the artist's achievement in making the work, and the manner in which the artwork evokes cognitive, perceptual, and emotional responses. Deep appreciation typically involves the ability to offer detailed descriptions of the artwork and the achievement it manifests. Deep appreciation, then, requires significant background knowledge and preparedness which may be absent in ordinary appreciation.

I have claimed that, on an acceptable account of aesthetic appreciation, it should turn out that most people are capable of appreciating artworks. This constraint does not apply to accounts of deep appreciation: it may turn out that some, or many, people have never had experiences of deep appreciation. It is not elitist to acknowledge that when a person has made a special effort to develop competence with respect to a given art form, be it painting or hip hop, she will be able to appreciate the work more fully by virtue of her better grasp of the work itself and the art-historical relations in which it stands. Nor would I automatically rule out accounts on which the deepest forms of appreciation require a capacity that is rare or even absent in humans. Perhaps the ability to appreciate art to the very fullest extent is among humans' many limitations.

How does introspective awareness figure in aesthetic experience, aesthetic appreciation, and deep aesthetic appreciation, respectively? Introspective awareness of the kind called into question by Nisbett and Wilson (1977) and their successors is unnecessary for aesthetic experience. Some awareness of one's own perception is necessary for aesthetic experience-one cannot have an aesthetic experience of perceptual information that one is unaware of taking in and processing (as when one is driving a long distance and 'zones out' for a while) (Irvin 2008a). However, the ability to observe one's own mental process and understand precisely why one feels moved by a piece of music or a natural environment, or which aspects of the object are responsible for one's feeling, should not be required. (Second-order awareness may nonetheless be implicated in some forms of aesthetic experience, as Carroll and Levinson suggest.)

\footnotetext{
${ }^{17}$ I defend a similar notion of aesthetic experience in Irvin (2008a) and (2008b). Perhaps aesthetic experience must involve an object cognized in such-and-such a way, where the aesthetic response one has is not inappropriate to an object thus cognized, though the object has been cognized incorrectly. I take some inspiration for this possibility from Carroll (1993).

${ }^{18}$ I qualify this claim to allow that an accurate grasp of the work may sometimes yield a response that is not apt to it, as when a work triggers an anxiety response in a viewer with a specific phobia. Perhaps a viewer in the grips of such a response is not appreciating the work, despite having correctly apprehended it.
} 
What about ordinary aesthetic appreciation? Does it require introspective awareness of mental processes? No. Aesthetic appreciation of an artwork requires a sufficiently accurate grasp of the work, and some of the problems identified above would threaten this: when a position effect influences one's perception, leading one to think that two (virtually) identical objects differ in specific qualities, one's grasp of (at least one of) them is significantly compromised. For ordinary appreciation, though, it is sufficient to have a reasonable grasp of the object itself without having insight into what it is about the object that causes one to enjoy it or to evince a particular response to it. Aspects of the musical structure of an R\&B song may cause me to make certain choices in how I dance, or to feel especially moved, but I can appreciate the music aesthetically without understanding how these effects are achieved or which elements of the music are responsible.

Deep aesthetic appreciation involves understanding of how the artwork achieves its effects, and thus significant insight into mental processes. When we learn how particular emotional effects in film are achieved through subtle techniques we had not previously noticed, this increases the depth of our appreciation.

Is the required insight into mental processes feasible, given the empirical results? The studies typically pose a direct challenge only to introspective memory, not to real-time introspective awareness, since they ask subjects to make reports after the fact. But this is not especially comforting; it seems unlikely that subjects who failed to report the role of the hint in helping to solve the cord-swinging problem were, in fact, aware of the role of the hint when they came up with the solution, but then forgot. Similarly, it seems unlikely that subjects knew that a position effect influenced them in choosing the stockings on the right, but then forgot this when asked to explain their choices. ${ }^{19}$

The studies show that we often lack introspective awareness of the way the mind brings together a variety of considerations to come up with a choice or evaluation. This does not imply that we have no introspective awareness at all. The biggest threat is to introspective awareness of processes, not of states. The studies don't suggest that I can't recognize that I am hungry, that I am sad, that I am smelling cinnamon, or that I am having an occurrent thought about bicycles. What is most troubling is that I may weave my awareness of such states into a tale about my evaluation of an object and believe that this tale actually explains the evaluation, when in fact it simply masks unconscious processing that may not have appealed to the same factors mentioned in the tale.

The studies also suggest that introspective knowledge or memory of particular states is often absent or misleading. The feel of two (more or less) identical pairs of stockings against my fingers, or their appearance when held up to the light, is surely quite similar. ${ }^{20}$ It appears that subjects misapprehend or misremember their own states of perceptual consciousness when they explain their evaluations.

${ }_{19}$ This is not to deny that verbal reports of mental processes are somewhat more accurate in real time than after the fact (Ericsson and Simon 1993).

${ }^{20}$ I will here leave aside the important possibility that subjects in the grip of a position effect unconsciously manipulated the stockings in such a way as to confirm a prior bias toward the right-hand pair, e.g., 
We thus have two problems: lack of introspective awareness of mental processes, and misleading introspective access to or memory of mental states. I propose that we tackle these problems separately.

\subsection{Introspective Awareness of Perceptual States}

When people attempt to give verbal explanations for their preferences, this causes the quality of those preferences to deteriorate. But another avenue may be more promising: learning to pay closer attention to occurrent perceptual states. Notoriously, we filter huge amounts of incoming perceptual data out of explicit consciousness, even when we are behaviourally responding to some of it. But it is possible to bring into awareness states that we have previously glossed over. ${ }^{21} \mathrm{~A}$ number of Buddhist-derived meditation practices are devoted to bringing more of our experiential states into explicit consciousness while suspending the evaluative mechanisms that tend to distort our awareness. The aim of mindfulness meditation is to maintain non-judgemental awareness of all aspects of one's experience, including perceptions, bodily sensations, thoughts, and feelings. Long-standing claims by meditators about improvements in their perceptual acuity, attention, and cognitive processing have been increasingly validated through empirical research, though further investigation is needed. ${ }^{22}$

Mindfulness techniques improve ability to detect stimuli and accurately identify their properties. They reduce attentional blink, or the period of time after stimulus detection before a similar stimulus can be detected again (Brown et al. 1984a, 1984b; May et al. 2011; Slagter et al. 2007; Slagter et al. 2009), improve the speed of encoding of visual information, thus allowing subjects to detect stimuli of shorter duration (Brown et al. 1984a, 1984b; Jensen et al. 2012), and improve reaction times to auditory stimuli (Lutz et al. 2009). They improve critical flicker fusion frequency, a measure of visual acuity reflecting one's ability to detect that a figure is flickering rather than steady (Manjunath and Telles 1999; Raghuraj and Telles 2002; Telles et al. 1995, 2007; see Cahn and Polich 2006 for discussion). They also reduce susceptibility to optical illusion (Telles et al. 1997, 2007).

On attention-related tasks, mindfulness techniques improve performance, shorten response times, and reduce error rates (Jensen et al. 2012; Jha et al. 2007; Semple 2010; van den Hurk et al. 2010). They also improve working memory (Jensen et al. 2012) and executive function, which refers to cognitive processes that govern other cognitive processes, such as the switching of attention from one task to another (Zeidan et al. 2010).

Some of the most promising results are from sport psychology. Moore (2009) and Gardner and Moore (2012) review findings that athletes trained in mindfulness improve on measures of attention as well as performance. Many studies found improvements in

by stretching the stockings more thinly and then pronouncing on their superior sheerness. The discussion of mindfulness below offers hope that subjects could learn not to engage in such manipulations.

${ }^{21}$ See also Irvin (2008a).

${ }^{22}$ In this brief summary I include only intervention studies, not correlational or case studies. 
performance, operationalized as coach ratings of performance (Gardner and Moore 2007), objective performance on training equipment (Fernández García et al. 2004), and national rankings (Bernier et al. 2009). Other studies suggest mechanisms of performance improvement: Hasker (2010) found improvements in 'ability to describe and to be non-reactive towards... internal experiences' and 'increased experiential acceptance', which is related to a reduction in avoidance of negative experiences (p. iv); Thompson et al. (2011) found improved ability to act with awareness and reduced task-related worries and task-irrelevant cognitions. Finally, in analysis of a study unrelated to sports performance, Kass et al. (2011) suggest, 'Mindfulness training may greatly impact actual driving performance over time by improving drivers' awareness of their environment and enabling them to block out distractions and to quickly identify hazards' (p. 236).

How are these results relevant for our purposes? Mindfulness training enhances perceptual acuity and speeds processing, making it more likely that people will accurately detect the features of an object. It increases awareness of one's inner experiences and improves working memory. All of these effects have promise for combatting coarse-grainedness: if one is better able to detect the features of the object and one's own perceptual experiences, and better able to hold this information in mind, one is more likely to be responsive to the relevant features of the object. Mindfulness training also improves executive function, reducing the attention paid to distractions and enhancing focus on relevant information. This has clear promise for combatting the problem of irrelevance. Moreover, these improvements in acuity and attention have pay-offs for athletic performance, which further supports the idea that mindfulness training enables subjects to detect and maintain focus on relevant rather than irrelevant aspects of their inner and outer experience.

Obviously, these results are suggestive rather than decisive when it comes to aesthetic judgement. To my knowledge, no studies have measured whether mindfulness training enhances one's ability to notice and respond to the aesthetically relevant features of a poem or painting. But the mounting evidence in other domains invites the hypothesis that the cognitive, perceptual, and attentional effects of mindfulness training would enhance aesthetic judgement. Assuming that our perceptual states themselves are not massively misleading as indicators of the entities being perceived-and nothing in the research calling introspection into question suggests that they are-perceptual mindfulness seems to be right sort of thing to allow us to appreciate artworks in the way that Carroll requires, by attending with understanding to their formal features, and to be in the aesthetic state of mind as Iseminger requires, by tracking the work's formal and aesthetic features and valuing the very experience of thus tracking them.

\subsection{Deep Aesthetic Appreciation and Awareness of Mental Processes}

Mindfulness training might allow us to develop greater awareness of our occurrent thoughts and emotional states as well as perceptual states, and this would have the 
potential to inform us about the interrelations, in our own minds, of elements of perception, cognition, and emotion. But will this be sufficient for views that seem to require awareness of how our mental processes function? Even if we can develop greater awareness of our occurrent perceptual, cognitive, and emotional states, it appears that without access to underlying processes or the ability to run controlled experiments on ourselves, any such information we might obtain will be only correlational, not causal. And some of the accounts we have considered seem to require information about how our responses are caused. One variety of aesthetic experience, on Carroll's account, is attention with understanding 'to the ways in which [the work's formal and aesthetic properties] engage our sensibilities and imagination' (Carroll 2002: 167). Kieran suggests that part of appreciating an artwork is appreciating 'the ways in which the artistry shapes and guides our responses' (Kieran 2005: 213). These are clearly causal notions. ${ }^{23}$

But I suggest that invoking an external theory about how one's own responses and those of others are produced, as part of one's deep appreciation of an artwork, is not, in fact, such a troubling thing. For deep appreciation is aimed at identifying values in a work that are accessible intersubjectively, not merely to the individual appreciator. To deeply appreciate a work is not merely to be sensitive to how it affects me: for my own responses may be grounded in or dependent on idiosyncrasies in my own experiences or perceptual mechanisms. To the extent that this is true, a work that is very valuable to me may not be very valuable simpliciter, and identifying the mechanisms whereby the work produces idiosyncratic responses is not germane to deep appreciation.

When we consider Carroll's and Kieran's accounts in relation to the idea of deep appreciation, then, we should take seriously their use of the plural: it is how the work 'engages our sensibilities and imagination', 'shapes and guides our responses', that is at issue. And an accurate theory of how responses are produced by various aspects of the artwork, abetted by observations of one's own states that are consistent with the theory, may be just the right sort of thing to invoke here.

We might wonder whether explanation-induced instability and deterioration will follow upon attempts to understand and explain our responses in these ways. If we attempt to bring external theories to bear in understanding our responses, will this change our preferences, and in objectionable ways? The experimental results I have discussed don't give us insight into this, since they involve subjects who attempted to introspectively observe or recollect their mental processes without appeal to accurate theories.

It stands to reason that bringing accurate theories to bear will sometimes alter our judgements. If I become aware of position effects on judgement, I may be in a position to attend especially carefully to the features of the object in order to avoid being

${ }^{23}$ But recall that on Kieran's view, perhaps one need only know that the work has caused one's responses and not how. 
influenced by such effects. ${ }^{24}$ This sort of judgement instability is hardly objectionable: it is a straightforward improvement. The greatest worry, perhaps, is that my immersive experience may be compromised by my attempts to observe, in real time, how particular features of the work affect me. If, in watching a scene in a movie, I am attending to the extremely slow zoom in on a character's face in relation to a theory about how this manoeuvre evokes emotion, this may disrupt my emotional response.

If I am relying on an accurate theory of how people's responses are produced by particular aspects of the artwork, should it matter that I myself do not experience the relevant response? Should I not simply be able to attend to the artwork and cross-reference its features with my theory in order to detect how it shapes and guides 'our' responses in general? Worries about particularism suggest that one's actually having the response is important: in the absence of the response, it is always possible that the response that would typically be evoked by a given element has been disabled or reversed, within the context of this particular work, by some other factor that one's theory has not taken into account. ${ }^{25}$ In so far as aesthetic appreciation is thought to be experiential, having the response is necessary. And if one's aesthetic response is hindered, one is not having as strong or satisfying an experience as one otherwise would, which is undesirable in itself.

I see two possibilities to mitigate the worry that applying theoretical knowledge to a work will undermine aesthetic responses. First, it may be that theoretical knowledge about how particular aspects of a work affect our responses is disruptive when first acquired, but over time can come to coexist with responses that are restored to, or even enhanced relative to, their initial intensity. ${ }^{26}$ Second, there may be more than one mode in which a work can be experienced, and it may be possible to learn to shift among these modes. It may be possible to experience a work immersively, experiencing and enjoying the effects it produces on us, and then later to experience it more analytically, with specific attention to the aspects that our theoretical knowledge tells us should be operative in producing our responses.

\subsection{Conclusion}

To sum up: aesthetic experience, appropriately construed, is not threatened by the problems I enumerated above. This is because an experience need not include an accurate grasp of its object to be aesthetic.

(Mere) aesthetic appreciation, which in my view does require a sufficiently accurate grasp of its object but does not require attention to one's own mental states or

\footnotetext{
${ }^{24}$ While I know of no studies testing this hypothesis in relation to position effects, Beaman et al. (1978) demonstrate that awareness of the bystander effect reduces its power.

${ }_{25}$ As Sibley $(1959,1974)$ observes, a feature that is good-making in one context may be neutral or even bad-making in another; and the factors that influence the feature's valence may be so complex that it is impossible to spell out what they are.

${ }^{26}$ DeBellis (1995) explores in depth the relation between the non-conceptual listening of ordinary, musically untrained listeners and the conceptual listening of trained listeners to music, concluding that training
} 
processes, is threatened by irrelevance and coarse-grainedness. However, to the extent that these problems rear their heads in unusual cases, this need not worry us exceedingly. Also, mindfulness training may mitigate these problems, helping us to grasp objects more accurately while weeding out distorting factors.

Deep aesthetic appreciation is threatened by all of the problems, because deep appreciation requires understanding of how our responses are produced by the work. However, introspection of one's own mental processes, which is seriously called into question by the empirical work, may not be required. Introspective access to the flow of one's occurrent perceptual, cognitive, and emotional states, combined with accurate theoretical knowledge about causal relations between aspects of a work and people's responses, may be sufficient to allow us to assess the work's merits as deep appreciation requires. This may involve the cultivation of particular kinds of cognitive skills, such as the ability to shift between modes of experience of a work. As long as it is possible to acquire such skills-and the empirical results surveyed here provide no reason to doubt this-deep appreciation will turn out to be challenging, but attainable.

What, then, is the ultimate impact of the empirical findings on the contemporary views of aesthetic experience and appreciation with which I began? Take, again, Kieran's (2005: 213) claim, 'When we truly appreciate a work, we appreciate its pictorial composition, the arc of the lines, the shading, the foreshadowing, the ways in which the artistry shapes and guides our responses.' Kieran's claim falls under my notion of deep appreciation. If his requirement that we appreciate 'the ways in which the artistry shapes and guides our responses' were a requirement for introspective awareness of these matters, it would be threatened by the empirical findings. However, if it is possible to appreciate these matters by applying theoretical knowledge about mental processes to introspective awareness of our states, then Kieran's view, even on a strong reading of his requirement, survives the empirical challenge.

Carroll (2002: 167) says that 'attention with understanding ... to the ways in which [the work's formal and aesthetic properties] engage our sensibilities and imagination' is one variety of aesthetic experience. I agree that this sort of attention could figure in aesthetic experience or mere aesthetic appreciation, though I take it to be required only for deep appreciation. Carroll's condition is similar to Kieran's, and the impact of the empirical challenge is similar as well: if Carroll means, here, to require direct introspective awareness of these processes, that may turn out to be impossible for many or most of us; but if a theoretical grasp of processes, combined with introspective awareness of occurrent states, is sufficient, then this variety of aesthetic experience remains possible, though perhaps challenging to achieve. Because Carroll requires 'attention with understanding' for this variety of aesthetic experience, it is not clear that the cocktail of theoretical knowledge of processes and introspective awareness of the flow of occurrent states would satisfy him. But perhaps 'attention' to the occurrent states, combined with 'understanding' of processes at a theoretical level, could do the trick. 
Iseminger (2005: 99) suggests that ' $[\mathrm{s}$ ] omeone is appreciating a state of affairs just in case she or he is valuing for its own sake the experiencing of that state of affairs.... In so far as experiencing a state of affairs involves having a sufficiently accurate grasp of it, Iseminger's notion will map onto my notion of aesthetic appreciation. It appears that a grasp of the flow of one's occurrent states, even without a grasp of the processes by which they are produced, may be sufficient to count as experiencing of a state of affairs, as long as those occurrent states don't mislead one regarding the state of affairs; and there is no obvious barrier to valuing this flow of occurrent states. If it is possible to gain greater introspective access to our perceptual states through mindfulness techniques, thereby staving off irrelevance effects, aesthetic appreciation in Iseminger's sense is safeguarded.

Levinson (forthcoming) says, 'Aesthetic experience is experience involving aesthetic perception of some object, grounded in aesthetic attention to the object, and in which there is a positive hedonic, affective or evaluative response to the perception itself or the content of that perception. ${ }^{27}$ If the requirement of 'aesthetic attention to the object' is strict, this is a notion of aesthetic appreciation; if not, it is an account of aesthetic experience. The empirical results don't give us deep reason to worry that we can't be aware of the content of our perception, or of the perception itself. The principal worry about Levinson's account is that the empirical results suggest a difficulty with knowing just what our 'hedonic, affective or evaluative response' is a response to: are we responding to the content of our perception, or is something else (e.g., a position effect) contributing to our response? This suggests not that aesthetic experience (or appreciation) is impossible, but that it may be difficult to know whether we are fulfilling the conditions for aesthetic experience or appreciation. I will not attempt here to assess how troubled we should be by this epistemic difficulty.

In sum, these accounts can be interpreted in such a way as to make their respective varieties of aesthetic experience or appreciation possible, given the empirical results. For some theories, this involves embracing theoretical, rather than introspective, awareness of mental processes. Whether their proponents would endorse these interpretations, however, is another question..$^{28}$

\section{References}

Beaman, Arthur L. et al. (1978). 'Increasing Helping Rates through Information Dissemination: Teaching Pays', Personality and Social Psychology Bulletin, 4: 406-11. Bell, Clive (1914). Art. London: Chatto and Windus.

ultimately enhances (rather than detracting from) the listener's ability to hear, and thus respond to, the fine details available in the music.

${ }_{27}$ Italics in original.

${ }^{28}$ I am grateful to Matthew Kieran and Jon Robson for helpful feedback on an earlier draft, to the volume editors for an invitation to the 2011 Challenges to Humanism: Character, Appreciation, and Value workshop in London, and to participants in the workshop for helpful discussion. 
Bem, Daryl J. and H. Keith McConnell (1970). 'Testing the Self-Perception Explanation of Dissonance Phenomena: On the Salience of Premanipulation Attitudes', Journal of Personality and Social Psychology, 14: 271-80.

Bergeron, Vincent and Dominic McIver Lopes (2012). 'Aesthetic Theory and Aesthetic Science: Prospects for Integration', in Arthur P. Shimamura and Stephen E. Palmer (eds), Aesthetic Science: Connecting Minds, Brains, and Experience. New York: Oxford University Press, 63-79.

Bernier, Marjorie et al. (2009). 'Mindfulness and Acceptance Approaches in Sport Performance', Journal of Clinical Sport Psychology, 25: 320-33.

Brown, Daniel et al. (1984a). 'Differences in Visual Sensitivity among Mindfulness Meditators and Non-Meditators', Perceptual and Motor Skills, 58: 727-33.

Brown, Daniel et al. (1984b). 'Visual Sensitivity and Mindfulness Meditation', Perceptual and Motor Skills, 58: 775-84.

Cahn, B. Rael and John Polich (2006). 'Meditation States and Traits: EEG, ERP, and Neuroimaging Studies', Psychological Bulletin, 132: 180-211.

Carlson, Kurt A. and Samuel D. Bond (2006). 'Improving Preference Assessment: Limiting the Effect of Context through Pre-Exposure to Attribute Levels', Management Science, 52: 410-21.

Carroll, Noël (1993). 'On Being Moved by Nature: Between Religion and Natural History', in Salim Kemal and Ivan Gaskell (eds), Landscape, Natural Beauty and the Arts. Cambridge: Cambridge University Press, 244-66.

Carroll, Noël (2002). 'Aesthetic Experience Revisited', British Journal of Aesthetics, 42: 145-68.

Coupey, Eloise et al. (1998). 'Product Category Familiarity and Preference Construction', Journal of Consumer Research, 24: 459-68.

Cutting, James (2003). 'Gustave Caillebotte, French Impressionism, and Mere Exposure', Psychonomic Bulletin and Review, 10: 319-43.

DeBellis, Mark (1995). Music and Conceptualization. Cambridge: Cambridge University Press.

Ericsson, Karl A. and Herbert A. Simon (1993). Protocol Analysis: Verbal Reports as Data, rev. edn. Cambridge, MA: MIT Press.

Fernández García, R. et al. (2004). 'Efecto de la hipnosis y la terapia de aceptación y compromiso (ACT) en la mejora de la fuerza física en piragüistas', International Journal of Clinical and Health Psychology, 4: 481-93.

Fleming, Stephen M. et al. (2010). 'Relating Introspective Accuracy to Individual Differences in Brain Structure', Science, 329: 1541-3.

Gardner, Frank L. and Zella E. Moore (2007). The Psychology of Human Performance: The Mindfulness-Acceptance-Commitment Approach. New York: Springer.

Gardner, Frank L. and Zella E. Moore (2012). 'Mindfulness and Acceptance Models in Sport Psychology: A Decade of Basic and Applied Scientific Advancements', Canadian Psychology, 53:309-18.

Goethals, George R. and Richard F. Reckman (1973). 'The Perception of Consistency in Attitudes', Journal of Experimental Social Psychology, 9: 491-501.

Hall, Lars and Petter Johansson (2008). 'Using Choice Blindness to Study Decision Making and Introspection', in P. Gärdenfors and A. Wallin (eds), Cognition: A Smorgasbord of Cognitive Science. Nora: Nya Doxa, $267-83$.

Hasker, S. M. (2010). 'Evaluation of the Mindfulness-Acceptance Commitment (MAC) Approach for Enhancing Athletic Performance'. Doctoral dissertation, Indiana University of Pennsylvania, Indiana, PA. 
Hume, David (1757/1985). 'Of the Standard of Taste' in Eugene F. Miller (ed), Essays Moral, Political and Literary. Indianapolis, IN: Liberty Fund, 226-49.

Hurk, Paul A. M. van den et al. (2010). 'Greater Efficiency in Attentional Processing Related to Mindfulness Meditation', Quarterly Journal of Experimental Psychology, 63: 1168-80.

Irvin, Sherri (2008a). 'Scratching an Itch', Journal of Aesthetics and Art Criticism, 66: 25-35.

Irvin, Sherri (2008b). 'The Pervasiveness of the Aesthetic in Ordinary Experience', British Journal of Aesthetics, 48: 29-44.

Iseminger, Gary (2005). 'The Aesthetic State of Mind', in M. Kieran (ed.), Contemporary Debates in Aesthetics and the Philosophy of Art. Oxford: Blackwell, 98-112.

Jensen, Christian Gaden et al. (2012). 'Mindfulness Training Affects Attention-Or is it Attentional Effort?', Journal of Experimental Psychology: General, 141: 106-23.

Jha, Amishi P. et al. (2007). 'Mindfulness Training Modifies Subsystems of Attention', Cognitive, Affective, \& Behavioral Neuroscience, 7: 109-19.

Johansson, Petter et al. (2005). 'Failure to Detect Mismatches between Intention and Outcome in a Simple Decision Task', Science, 310: 116-19.

Kass, Steven J. et al. (2011). 'Effects of Mindfulness Training on Simulated Driving: Preliminary Results', Mindfulness, 2: 236-41.

Kieran, Matthew (2005). Revealing Art. London: Routledge.

Kieran, Matthew, Aaron Meskin, and Margaret Moore (unpublished). 'Mere Exposure to Bad Art'.

Latané, Bibb and John M. Darley (1970). The Unresponsive Bystander: Why Doesn't He Help? New York: Appleton-Century Crofts.

Levinson, Jerrold (2014). 'Toward a Non-Minimalist Conception of Aesthetic Experience', in Aesthetics Pursuits: Essays in Philosophy of Art. Oxford: Oxford University Press.

Li, Ye and Nicholas Epley (2009). 'When the Best Appears to be Saved for Last: Serial Position Effects on Choice', Journal of Behavioral Decision Making, 22: 378-89.

Locher, Paul et al. (2007). 'Visual Interest in Pictorial Art during an Aesthetic Experience', Spatial Vision, 21: 55-77.

Lutz, Antoine et al. (2009). 'Mental Training Enhances Attentional Stability: Neural and Behavioral Evidence', Journal of Neuroscience, 29: 13418-27.

Maier, Norman R. F. (1931). 'Reasoning in Humans II: The Solution of a Problem and its Appearance in Consciousness', Journal of Comparative Psychology, 12: 181-94.

Manjunath, N. K. and Shirley Telles (1999). 'Improvement in Visual Perceptual Sensitivity in Children Following Yoga Training', Journal of Indian Psychology, 17: 41-5.

Mantonakis, Antonia et al. (2009). 'Order in Choice Effects of Serial Position on Preferences', Psychological Science, 20: 1309-12.

May, Christopher J. et al. (2011). 'Short-Term Training in Loving-Kindness Meditation Produces a State, But Not a Trait, Alteration of Attention', Mindfulness, 2: 143-53.

McLaughlin, John P. et al. (1983). 'Aesthetic Preference in Dextralsand Sinistrals', Neuropsychologia, 21: $147-53$.

Moore, Zella E. (2009). 'Theoretical and Empirical Developments of the Mindfulness-AcceptanceCommitment (MAC) Approach to Performance Enhancement', Journal of Clinical Sport Psychology, 25: 291-302.

Nisbett, Richard and Timothy Wilson (1977). 'Telling More than We Can Know: Verbal Reports of Mental Processes', Psychological Review, 84: 231-59. 
Raghuraj, P. and Shirley Telles (2002). 'Improvement in Spatial and Temporal Measures of Visual Perception Following Yoga Training', Journal of Indian Psychology, 20: 23-31.

Semple, Randye J. (2010). 'Does Mindfulness Meditation Enhance Attention? A Randomized Controlled Trial', Mindfulness, 1: 121-30.

Shusterman, Richard (1991). 'Form and Funk: The Aesthetic Challenge of Popular Art', British Journal of Aesthetics, 31: 203-13.

Sibley, Frank (1959). 'Aesthetic Concepts', Philosophical Review, 68: 421-50.

Sibley, Frank (1974). 'Particularity, Art and Evaluation', Proceedings of the Aristotelian Society, supp. 48: 1-21.

Slagter, Heleen A. et al. (2007). 'Mental Training Affects Distribution of Limited Brain Resources', PLoS Biology, 5: 1228-35.

Slagter, Heleen A. et al. (2009). 'Theta Phase Synchrony and Conscious Target Perception: Impact of Intensive Mental Training', Journal of Cognitive Neuroscience, 21: 1536-49.

Telles, Shirley et al. (1995). 'Improvement in Visual Perception Following Yoga Training', Journal of Indian Psychology, 13: 30-2.

Telles, Shirley et al. (1997). A Combination of Focusing and Defocusing through Yoga Reduces Optical Illusion More than Focusing Alone', Indian Journal of Physiology and Pharmacology, 41: 179-82.

Telles, Shirley et al. (2007). 'Effect of Yoga on Visual Perception and Visual Strain', Journal of Modern Optics, 54: 1379-83.

Thompson, Rachel W. et al. (2011). 'One Year Follow-Up of Mindful Sport Performance Enhancement (MSPE) with Archers, Golfers, and Runners', Journal of Clinical Sport Psychology, 5: 99-116.

Wilson, Timothy D. et al. (1993). 'Introspecting about Reasons Can Reduce Post-Choice Satisfaction', Personality and Social Psychology Bulletin, 19: 331-9.

Wilson, Timothy D. and Jonathan W. Schooler (1991). 'Thinking Too Much: Introspection Can Reduce the Quality of Preferences and Decisions', Journal of Personality and Social Psychology, 6o: 181-92.

Yamada, Ayumi (2009). 'Appreciating Art Verbally: Verbalization Can Make a Work of Art Be Both Undeservedly Loved and Unjustly Maligned', Journal of Experimental Social Psychology, 45: $1140-3$.

Zeidan, Fadel et al. (2010). 'Mindfulness Meditation Improves Cognition: Evidence of Brief Mental Training', Consciousness and Cognition, 19: 597-605. 